\title{
Las modalidades actuales del subimperialismo
}

Claudio Katz

Resumen: El subimperialismo se verifica en las ambiciones de Turquía, las aventuras de Arabia Saudita y la reconstitución de Irán. Ese estatus no se extiende a Israel, Canadá o Australia, mientras que Rusia o China actúan como imperios en formación. Tanto Brasil como Sudáfrica son formaciones intermedias con recortados sus márgenes de intervención externa. El concepto de subimperialismo permite clarificar escenarios de la época actual.

Palabras claves: Imperialismo. Geopolítica. Hegemonía.

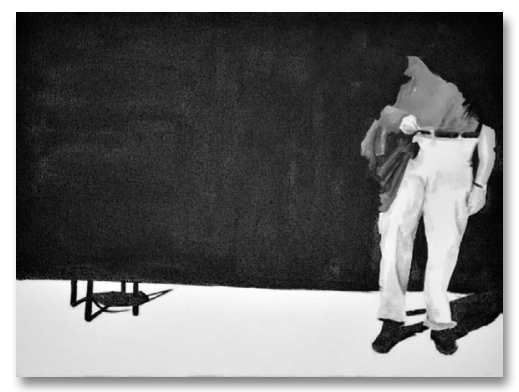

\section{The actual modalities of sub-imperialism}

\begin{abstract}
Sub-imperialism can be seen in Turkey's ambitions, Saudi Arabia's ventures and Iran's recovery. This status does not include Israel, Canada or Australia, while Russia and China act as empires in formation. Both Brazil and South Africa are intermediate formations with limited margins of external intervention. The category of sub-imperialism permits clarification of present-day scenarios.
\end{abstract}

Keywords: Imperialism. Geopolitics. Hegemony.

$\overline{\text { Claudio Katz }}$

Economista, investigador do CONICET, professor da UBA, membro do EDI. 


\section{INTRODUCCIÓN}

Los debates teóricos sobre el subimperialismo suscitan interés, pero el concepto es relevante si esclarece la realidad contemporánea. ¿Cómo se aplicaría en el contexto actual?

Abordamos este análisis a partir de una revisión teórica del concepto, que encaramos recordando cómo Marini asignó al subimperialismo una dimensión económica compensatoria del sub-consumo y otra geopolítico-militar de protagonismo brasileño. El pensador brasileño reconsideró la teoría clásica del imperialismo y registró la nueva hegemonía regional de ciertas formaciones intermedias.

Entendemos que la mundialización neoliberal diferencia a esas economías por su lugar en la cadena de valor y que el subimperialismo actual no tiene aplicaciones puramente económicas, ni se extiende a bloques de países. Rige para gendarmes asociados y autónomos de Estados Unidos, en un contexto donde los mecanismos de dominación global se han diversificado. Analizamos estos procesos en el artículo que antecede al siguiente texto ${ }^{1}$.

En la actualidad la categoría tiene especial vigencia para una región con prolongados escenarios de guerra como el mundo árabe. Esos conflictos involucran a potencias centrales (Estados Unidos, Francia, Inglaterra) y en recomposición (Rusia), junto a varios actores locales (Turquía, Arabia Saudita, Israel, Irán).

Ese conglomerado ha intervenido en confrontaciones que desembocaron en una tragedia sin límites. La responsabilidad de Estados Unidos salta a la vista. Anhela la apropiación del petróleo y el control de áreas estratégicas del comercio internacional. Sus presidentes comandaron la destrucción de Afganistán (ReaganCarter), Irak (Bush), Libia y Siria (Obama). Esa devastación incluyó aterradoras masacres, que implicaron 220.000 muertos en el primer país, 650.000 en el segundo y 250.000 en el cuarto.

En los últimos seis años el principal objetivo político de esa sangría fue el aplastamiento de la primavera árabe. Las revueltas fueron sofocadas mediante dictaduras (Egipto, Siria), retornos al viejo régimen (Túnez), invasiones (Libia) y masacres yihadistas (Siria).

1 Cf. Katz (2017b). 
Es evidente el protagonismo imperial en esa demolición. Pero Estados Unidos no actúa solo. Mantiene una estrecha conexión con tres potencias de la región (Turquía, Arabia Saudita e Israel) y oscila entre la amenaza y la negociación con otro contendiente decisivo (Irán). ¿Estos países operan como fuerzas subimperiales?

\section{EL PRINCIPAL PROTOTIPO}

El concepto le cuadra perfectamente a Turquía, que intervino en la reciente guerra de Siria siguiendo todas las reglas del subimperialismo. El gobierno de Erdogan buscó tumbar a su viejo rival Assad, para gestar un liderazgo zonal en alianza con la Hermandad Musulmana.

Ante el derrocamiento de su socio en Egipto y el peligro de gestación de un estado kurdo, el presidente turco consumó un espectacular viraje. Se sumó al bloque de rusos e iraníes que sostienen al régimen sirio. Como no logró primacía en el desplazamiento de su adversario optó por sostenerlo.

Este giro ilustra cómo desenvuelve Turquía su estrategia de hegemonía regional. Sus gobernantes acumulan gran experiencia en ese tipo de maniobras. Combinan la asociación con el distanciamiento de Estados Unidos.

Turquía es miembro de la OTAN y mantiene una aceitada conexión con el Pentágono. Alberga una base militar con ojivas nucleares apuntando a Rusia y ha enviado tropas a operaciones en Afganistán, Irak y Somalia.

Pero los gobernantes del país nunca actúan como simples policías regionales. Apuntalan apetitos expansivos de larga data. Por eso invadieron y ocuparon Chipre. La estrategia de resurgimiento neo-otomano no es una fábula nostálgica. Inspira un proyecto de hegemonía regional.

Esa pretensión se asienta en tradiciones despótico-estatistas recreadas por la tutela militar. A diferencia de América Latina o el sur de Europa, el fin de la dictadura no disminuyó en Turquía el peso dominante del ejército en la estructura política. Esa gravitación es un componente decisivo de la presión subimperial. 
Con ese belicismo se busca mantener la tasa de crecimiento que afianzó el perfil económico intermedio del país. Las corporaciones de origen turco operan desde los años 80 en varios países, a través de convenios de libre-comercio.

Estas características tornan apropiado el calificativo subimperial que utiliza un autor para retratar el perfil del país (ÇAĞLI, 2009). La política expansionista parece cuajar más con la fracción política islámica de la burguesía (Rabiismo), que con el viejo segmento atlantista (Kemalismo). El primer sector no le perdona al segundo haber aceptado el sometimiento a Occidente, en desmedro de la identidad sunita. Por eso intentan comandar ahora un proyecto de islamización regional (SAVRAN, 2016).

El perfil subimperial de Turquía incluye la opresión histórica de varias minorías nacionales. Especialmente los kurdos son víctimas de un orden autoritario que exige la total supremacía de una sola lengua, raza e idioma.

Lo mismo ocurrió con el genocidio armenio, perpetrado sobre el final de la Primera Guerra Mundial para construir un Estado homogéneo. La negación de esa masacre forma parte de la nacionalidad imaginada en la constitución de Turquía. Es un cimiento del proyecto de restauración neo-otomana (BATOU, 2015).

El carácter subimperial de Turquía se verifica también en una persistente disputa con Irán, que recrea antiguas rivalidades con el imperio persa. Esa competencia guía la política exterior del país y ha sido determinante de la intervención en Siria. Pero a ese choque tradicional se ha sumando otro inesperado contendiente con aspiraciones hegemónicas.

\section{UN ENSAYO AVENTURERO}

Las pretensiones subimperiales de Arabia Saudita han sido muy visibles en la guerra de Siria. La monarquía encabezó el sostén a los yihadistas para tumbar a Assad y su régimen criminal es el principal referente de los fundamentalistas.

El reino disputa hegemonía con Irán recurriendo a una antigua contraposición entre sunitas y chiitas, que se cobró un millón de muertos en la guerra entre Irak e Irán. No tolera la preeminencia 
lograda por sus adversarios en los gobiernos que sucedieron a Saddam Hussein. Exige además el sometimiento de todos los pobladores chiitas de la península arábiga, que encabezaron las protestas de la primavera árabe (JAHANPOUR, 2014).

Para constituirse como una fuerza subimperial, los sauditas han actuando con gran autonomía militar primero en Barhein y luego en Yemen. Comandan una atroz escalada de masacres en este estratégico enclave. Aprovechan la importante colaboración de Inglaterra y Francia, pero han desarrollado el grueso de las operaciones bélicas por su propia cuenta.

Siguiendo un principio básico del subimperio Arabia Saudita mantiene una estrecha asociación con el Pentágono. Es un gran cliente en la compra de armamento y su poder financiero apuntala al dólar como moneda mundial.

Pero al cabo de muchos años de manejo de una renta colosal, los monarcas han construido un poder propio, que genera múltiples conflictos con Washington. El petróleo es un área de controversia. Estados Unidos incrementó su abastecimiento interno, redujo la dependencia de los proveedores, utiliza la baratura del combustible como instrumento de presión sobre Rusia e Irán y afecta los negocios de los sauditas.

Los monarcas han respondido con cierta ambivalencia. Por un lado avalaron la caída del precio para obstruir la vulnerable rentabilidad de la producción norteamericana (extracción con shale). Pero también priorizaron la convergencia con Estados Unidos para disciplinar a la OPEP y debilitar a Teherán. Las nuevas aspiraciones subimperiales se nutren de esta gestión de los recursos petroleros.

El principal hito saudita en la consolidación de una fuerza propia ha sido el apadrinamiento de los yihadistas. Los monarcas protegen y financian a una variedad de grupos terroristas que desestabilizan a Occidente.

Esas organizaciones perfeccionan el terrorismo talibán, que Estados Unidos fomentó hace varias décadas para expulsar a la Unión Soviética de Afganistán. Forman redes que las potencias occidentales utilizan para destruir a los regímenes adversarios del mundo árabe. Esa demolición ha servido para sepultar los 
vestigios de laicismo y modernización cultural que despuntaban en esas sociedades.

Pero los fundamentalistas terminaron forjando una fuerza transfronteriza, que se alimenta del odio generado por las destrucciones imperialistas. Prometen una regeneración social fundada en estrictas normas de autenticidad religiosa. Esos principios incluyen alcanzar el paraíso a través de la inmolación suicida. Siguiendo la pauta de Bin Laden, los distintos grupos tienden a desenvolver acciones autónomas que escapan al control de sus creadores.

Arabia Saudita preserva esas organizaciones para apuntalar sus metas de hegemonía. Pero el futuro del reino es muy incierto. Varios estrategas del Departamento de Estado evalúan la conveniencia de acabar con el fundamentalismo neutralizando a la propia monarquía. Promueven incluso la balcanización de Arabia Saudita, para transformar a ese país en una colección de impotentes mini-Estados (KATZ, 2017a).

Los jeques garantizaron la pulverización de los adversarios seculares de Occidente. Pero su retrógrado régimen deteriora las alianzas con vertientes liberal-conservadoras, más subordinados a Estados Unidos. Este conflicto retrata la tensión potencial que genera la evolución subimperial de los sauditas (PETRAS, 2014).

\section{UNA INCIERTA RECONSTITUCIÓN}

Irán confirma el estatus cambiante del subimperialismo. Marini incluyó a ese país en su clasificación, cuando el Sha Palhevi actuaba como potencia regional, en sociedad con el Pentágono contra la URSS. El régimen teocrático que sustituyó a la monarquía no sólo dejó de ejercer ambas funciones. Ha chocado en forma muy aguda con Estados Unidos.

Su intervención reciente en Siria ratificó esa confrontación. También ilustró cómo los Ayatollahs apuntalan al régimen de Assad, para reforzar su preeminencia en Irak y contrarrestar el acoso saudita en Yemen. Participan en esos conflictos con armas, asesores y cierto despliegue de fuerzas regulares. Su ambición regional se verifica en el reclutamiento de chiitas, para disputar 
liderazgo con sus adversarios sunitas en todo el mundo árabe (BEHROUZ, 2017).

Irán negocia en forma directa con las grandes potencias. Ha permitido a Rusia incursionar desde su territorio contra los yihadistas, pero mantiene abiertas las tratativas nucleares iniciadas con Obama. Al cabo de varias décadas de aislamiento económi$\mathrm{co}$, el régimen acepta un desarme parcial a cambio de inversiones occidentales. Tramita un lugar protagónico en los gasoductos que diseñan las compañías petroleras (ARMANIAN, 2016).

Los socios privilegiados del capitalismo iraní se definirán en la intensa batalla interna que libra el ala pro-occidental (Rohani), con la vertiente tradicionalista (Jamenei). Todos buscan desactivar un descontento reformista, que amenaza la supremacía de los teólogos y militares en el manejo del gobierno.

Estados Unidos intentó destruir a Irán mediante guerras, sabotajes y embargos. Obama ensayó un giro negociador, pero el curso de esas tratativas es incierto. Todos conocen la capacidad potencial de Irán para reconstituir su incidencia como gran jugador subimperial.

La rivalidad en esos términos que mantienen Turquía, Arabia Saudita e Irán no se extiende a otros países como Egipto, cuyas ambiciones quedaron diluidas por el cúmulo de derrotas sufridas ante Israel. Esas frustraciones condujeron a un sometimiento total al Departamento de Estado.

Medio Oriente es un área de tensiones subimperiales por la continuada preeminencia de sociedades inestables. Todos los países cargan con las frustraciones generadas por el fracaso de la modernización secular. Persisten los poderes militares autocráticos asociados al mundo de los negocios, que utilizan la religión para legitimar su dominación (AMIN, 2011, p. 201-216).

En ese escenario los subimperios tradicionales (Turquía), nuevos (Sauditas) y en recomposición (Irán) disputan supremacía. Estados Unidos usufructúa con esos conflictos, apuntalando periódicamente a una subpotencia contra otra. Busca desgastar a todos para mantener un balance de poder. En esta maquiavélica acción, el imperialismo central remodela su propio control sobre aliados y contrincantes. 


\section{APÉNDICES COIMPERIALES}

Entre los socios de Estados Unidos que desenvuelven intereses propios, Israel fue catalogado por Marini como un subimperio. Ciertamente presenta muchos rasgos de ese tipo. Pero tiene más parecidos con los países orgánicamente integrados al imperialismo colectivo. Este último grupo opera como una prolongación directa de los centros y correspondería asignarle otra denominación. Más que socios son apéndices de esa estructura.

La compenetración de esos países con sus hermanos mayores induce a identificarlos con "provincias externas" de Estados Unidos (AMIN, 2012), "imperialismos secundarios" (BOND, 2015, p. 15-16) o "mini-imperios" (PETRAS, 2014). Esta performance asemeja a Israel con Canadá y Australia.

En los tres casos prevalece una adaptación contemporánea a la gestión imperial. No son viejas potencias subordinadas en forma silenciosa (Inglaterra) o conflictiva (Francia) al líder norteamericano. Tampoco han transitado por experiencias previas de ambición global (Alemania, Japón) o preeminencia colonialista (España, Portugal, Holanda).

Israel, Canadá y Australia ocupan un lugar clave en la custodia del orden global. Por su total amalgama con Pentágono y la OTAN no participan del conglomerado subimperial. Tanto en la coordinación económica, como en la acción política y la coerción militar, los tres países actúan más como prolongaciones que como asociados de Estados Unidos.

Conforman Estados que nunca desplegaron gran autonomía, ni se involucraron en los conflictos que caracterizan a los subimperios. Remodelan sus acciones en consonancia con su tutor y garantizan, a escala regional, los mismos intereses que Estados Unidos asegura a escala global.

Esa articulación con el poder norteamericano tiene un cimiento histórico en el legado común de sociedades gestadas por colonos de piel blanca. Comparten la misma herencia de racismo, exterminio de pueblos originarios, ocupación de tierras ajenas y prejuicios ideológicos euro-centristas. 
Esa afinidad de Israel, Canadá y Australia facilita un predominio de políticas explícitamente pro-occidentales, que no se verifica en Turquía, Arabia Saudita o Irán.

Por estas razones Israel no cumple en Medio Oriente funciones equivalentes a sus competidores. Actúa como exponente de un lobby sionista, directamente enlazado al aparato estatal estadounidense. Esta diferencia cualitativa lo separa de otros socios de Norteamérica en la región.

Aunque Turquía tiene bases de la OTAN, Egipto es el gran receptor de armamento yanqui y Arabia Saudita es un sostén financiero del dólar, Israel cuenta con privilegios que la primera potencia no extiende a ningún otro aliado.

El origen de esa preferencia es la sintonía de Estados Unidos con el colonialismo tardío de Israel. Este país recrea todos los mecanismos de la opresión occidental. Propicia la anexión territorial, la democracia de exclusión, la expulsión de la población autóctona y la creación de una masa de refugiados. En nombre de la reparación histórica del holocausto, ejerce el terrorismo de Estado en los territorios ocupados (KATZ, 2007).

La integración israelí al poder estadounidense se afianzó luego de varias guerras con los vecinos árabes. Mantiene igualmente conflictos recurrentes con el Departamento de Estado. El belicismo sionista asegura el control imperial de la región, pero obstruye la flexibilidad de la política exterior yanqui. Destruye mercados y aliados posibles, impone guerras adicionales y genera problemas en el manejo del petróleo.

Estas tensiones alcanzaron un punto crítico en la última fase de la administración de Obama. En alianza con los republicanos, Netanyahu impugnó en inéditos términos el acuerdo con Irán. Israel intenta ahora la captura completa de Cisjordania para liquidar la farsa de los dos Estados.

Con ese objetivo incentivó la demolición de un adversario sirio que albergó a los palestinos. El gobierno israelí no acepta perder el monopolio atómico regional frente a las instalaciones construidas por los Ayatollahs y boicotea el convenio suscripto para desmantelar esas estructuras. 
¿Modificarán esas tensiones el estatus de Israel? ¿Sustituirá su rol de apéndice estadounidense por un papel semejante a los subimperios? Es una posibilidad derivada del carácter cambiante de esas configuraciones. Irán es un ejemplo de esas mutaciones. Pero la trayectoria de Israel induce al país a una permanencia en su condición de prolongación imperial.

\section{CONTRAPUNTO DE SITUACIONES}

Australia es otro caso de un ensamble total con las potencias centrales. Algunos estudios utilizan el término "coimperialista" para definir ese posicionamiento (DEMOCRATIC, 2001). Desenvolvió esa función, desde los servicios que prestó a Gran Bretaña para bloquear el ingreso de rivales (Alemania y Japón, Francia), a una alejada zona del Pacífico.

Posteriormente Australia recreó todas las formas del imperialismo tradicional. Consolidó la primacía de la acción militar, el chauvinismo y la ideología racista. Ese acervo opresivo le permitió integrarse a la política militar norteamericana, para jugar un papel contrarrevolucionario en Corea, China, Vietnam e Indonesia. En los últimos años asumió un rol policial en Timor y facilitó las iniciativas propiciadas por Estados Unidos en desmedro de Portugal.

Pero en ese papel de custodio imperial Australia también afianzó la presencia de sus empresas. Exportó capital y se transformó en un gran artífice del capitalismo en el Pacifico. En la última década protagonizó otra reconversión y retomó su especialización en la exportación de los minerales requeridos para la industrialización asiática. Esta sucesión de cambios se consumó remodelando su estatus coimperial.

Canadá es un caso semejante de alta participación en incursiones militares externas. Las empresas del país consolidaron, además, un fuerte integración con Estados Unidos. El correlato de esos negocios ha sido una mayor atadura a las demandas del Pentágono.

Israel, Australia y Canadá no se amoldan, por lo tanto, al sentido que Marini asignó al subimperialismo. La aplicación de este concepto podría en cambio extenderse a India, que ejerce un rol 
parecido a Turquía en su zona de influencia. Mantiene una relación análoga de asociación, autonomía y dependencia con Estados Unidos.

La ubicación de India en el casillero subimperial es congruente con la omnipresencia regional de su ejército. Interviene activamente en la convulsión de Sri Lanka, en las tensiones de Bangla Desh y en los conflictos con Nepal.

Sus fuerzas armadas continúan actuando en Cachemira al cabo de cuatro guerras con Pakistán. Esa misma presencia se verifica en las disputas fronterizas con China. Luego del choque militar de 1962 persiste la indefinición del futuro de Tíbet. El ejército cumple también un papel central frente a la oleada de terror talibán, en un contexto de gran opresión de las minorías musulmanas.

El perfil subimperial de India se nota en los giros de sus clases dominantes. Adoptaron el credo neoliberal luego del desplome de la URSS y aprovecharon la complicidad del ejército pakistaní con los talibanes, para apuntalar su confluencia con Estados Unidos.

Este enorme protagonismo geopolítico de India diferencia al país de otras economías semiperiféricas. Sus pretensiones regionales expansivas se corroboran en el plano de la ideología y la religión (MORALES RUVALCABA, 2013). India y Turquía ilustran modelos de subimperialismo que no se aplican a Israel, Canadá o Australia.

\section{PECULIARIDADES DE OTRA POTENCIA}

Es intuitivamente evidente que Rusia difiere de los subimperios. No es ubicada en ese casillero por quienes resaltan ese rasgo en los BRICS. Todos perciben que es una configuración de otra especie.

Rusia no ejerce el rol de gendarme complementario que caracteriza a los subimperios. Es una potencia militar en continuo choque con Estados Unidos. Albergó, además, durante la mayor parte del siglo XX, un sistema no capitalista conflictivo con cualquier modalidad de imperialismo contemporáneo.

Rusia afronta una inserción económica internacional vulnerable (DZARAZOV, 2015). Se asienta en el extractivismo y la 
explotación extensiva de los recursos naturales y no ha superado la crisis demográfica y el estancamiento industrial que sucedió al colapso de la URSS.

Exporta materias primas y preserva una industria poco competitiva. Los oligarcas que se apoderaron de las propiedades estatales invierten poco, especulan en los mercados financieros y protegen gran parte de sus fortunas en el exterior.

Luego de la devastadora experiencia del neoliberalismo extremo que encabezó Yelstin, la restauración capitalista fue remodelada con una gestión autoritaria. Putin reintrodujo el control estatal, limitó el saqueo y recuperó la gravitación militar del país. Esa reconstitución incluyó la reivindicación del patriotismo ruso y un retorno al padrinazgo sobre las zonas fronterizas (PRÉSUMEY, 2015).

El desplome de la Unión Soviética precipitó la separación de 14 repúblicas no rusas y el resurgimiento de conflictos con otras 21 naciones, que ocupan el 30\% del territorio. La permanencia de ese vecindario bajo la égida de Moscú es la prioridad geopolítica del Kremlin.

Ese control se reavivó bajo la dura presión de Occidente. Con la segunda guerra de Chechenia (2000), la respuesta militar en Georgia (2008) y la reintegración de Crimea (2014), Putin puso freno a la pretensión norteamericana de convertir a Rusia en un vasallo.

Esta actitud defensiva frente al imperialismo - junto a una conducta ofensiva hacia los vecinos - explica el peculiar posicionamiento externo de Rusia. Se asemeja a los subimperios en la búsqueda de supremacía regional, pero soporta un hostigamiento estadounidense que lo distancia de esa condición. Rusia combina la protección de sus fronteras con la ambición de forjar una estructura propia de dominación.

Esa contradicción difiere de los dilemas que afrontan Turquía, Arabia Saudita o India. Rusia no mantiene una relación de asociación y autonomía con Estados Unidos, sino una tensión estructural de gran alcance. Por eso no le cuadra la categoría subimperial. Las clases dominantes aspiran a un estatus más significativo, a pesar del carácter embrionario de ese anhelo. 


\section{IMPERIO EN FORMACIÓN}

La fórmula que más se ajusta al perfil actual de Rusia es imperio en formación. Implica la preeminencia de un proceso muy incompleto y provisorio. Se podría utilizar también otras denominaciones como semi-imperio, pre-imperio o proto-imperio. Este último concepto alude a una formación ya contenida en la estructura actual. Es semejante a la proto-industrialización (fabricación a domicilio), que anticipó la manufactura en el debut del capitalismo.

Algunos analistas estiman que Rusia es un imperio consumado, que desenvuelve conductas de gran potencia en los choques con sus rivales (POZO-MARTIN, 2015, p. 207-219). Pero omiten registrar que no se trata de una confrontación entre pares. Existe un abismo de poder entre Rusia y sus contendientes de Occidente.

La descripción del país como un imperio ya establecido resalta una historia de colonización interna, tanto en el periodo feudal, como en la era soviética y en la actualidad (KOWALEWKI, 2014). Pero es cuestionable afirmar que Rusia es un imperio porque ya lo era anteriormente. Se olvidan las enormes mutaciones registradas al cabo de tantos siglos.

Es particularmente problemático suponer que durante 70 años de régimen no capitalista perduró ese hilo de continuidad imperialista. Con ese criterio se diluye la definición de ese estatus en relación a los regímenes sociales vigentes en cada momento. No se entiende con qué interpretación de imperialismo se trazan equivalencias entre el imperio zarista, soviético y contemporáneo.

En la vereda opuesta de esa caracterización se ubica la presentación de Rusia como un faro del antiimperialismo contemporáneo (ESCOBAR, 2014). Este enfoque suele incluir elogios a Putin, como lúcido conductor de la resistencia a Estados Unidos.

Esta descripción repite razonamientos de la vieja ortodoxia comunista olvidando que la URSS desapareció. Rusia está gobernada actualmente por capitalistas que priorizan su propio bienestar. Afronta tensiones con Estados Unidos desde la perspectiva de una potencia opresiva en ciernes.

La enemistad de Occidente no convierte al gobierno ruso en defensor de los desposeídos. Es totalmente válido centrar los cañones en el enemigo principal, pero es ingenuo embellecer a un imperio naciente. 
Equiparar a Rusia con Estados Unidos es tan equivocado como contrastarlos, imaginando antagonismos definitivos entre formaciones capitalistas. Un imperio en gestación y otro dominante no son iguales, pero tampoco se ubican en polos contrapuestos.

El estatus de Rusia se clarifica analizando su relación con las potencias centrales y su vecindario. Los criterios expuestos por Lenin a principios del siglo XX no resuelven ese problema y su esquemática aplicación conduce a razonamientos abstractos.

Algunos autores afirman, por ejemplo, que Rusia no es imperialista por el reducido papel de los bancos internacionales y las exportaciones de capital (ANNIS, 2014). Otros entienden que sí es imperialista por la influencia de los monopolios y las inversiones externas (SLEE, 2014).

Pero el líder bolchevique utilizaba parámetros de ese tipo para definir las peculiaridades de una etapa del capitalismo. No pretendía clasificar a los países. Con ordenamientos atados a esas características, una potencia de la centuria pasada tan aguerrida como Japón, quedaría excluida del club imperial.

Rusia actúa como un imperio en constitución. Su comportamiento en el reciente conflicto de Ucrania confirma ese perfil. Estados Unidos aprovechó la oleada de protestas contra el gobierno autocrático de ese país, para favorecer el copamiento derechista de una revuelta e inducir un golpe de Estado. Pretendió transformar a Ucrania en satélite de la OTAN, para consolidar el cerco de misiles que estableció en Polonia, Estonia Letonia y Lituania (ROZHIN, 2015).

Putin respondió con la asimilación de Crimea y consintió la resistencia en el Este ucraniano (Donetsk) contra el gobierno reaccionario de Kiev. Pero bloqueó las acciones autónomas y radicales de esos sublevados (DOLCEROCCA; TERZIOGLU, 2015).

Lo ocurrido ilustró cómo Obama intentó debilitar a Rusia para quebrar cualquier alianza autónoma con Europa. También demostró que Putin resiste esa andanada para reconstruir la hegemonía regional del país. El Departamento de Estado utilizó sus agentes en Kiev y el Kremlin respondió con jugadas de fuerza en Crimea y Siria. El imperialismo central y su rival en formación ratificaron su naturaleza en esas batallas. 


\section{OTRA VARIANTE EN GESTACIÓN}

También China podría ser caracterizada como un imperio en constitución. Esa fisonomía se verifica observando cómo el pasaje de un régimen burocrático a otro capitalista ha modificado la política exterior del país. Ya es una potencia embarcada en proyectos de alcance global (ROUSSET, 2014).

Este carácter mundial (y no meramente regional) de la estrategia seguida por el gigante asiático, induce acertadamente a rechazar su clasificación dentro del conglomerado subimperial (LUCE, 2015, p. 38-39).

La aplicación del concepto es inadecuada en este caso por la tensión estructural que mantiene el país con Estados Unidos. En este plano se asemeja a Rusia y se diferencia de Turquía o India. La potencia oriental no integra la OTAN, sino que es hostilizada por el Pentágono. No forma parte del orden imperial actual, sino que rivaliza con esa estructura. Por esa razón se perfila como un imperio en gestación y no como otro eslabón del circuito subimperial.

A pesar de su apabullante presencia económica, del peso de sus exportaciones y la magnitud de sus inversiones foráneas, China no es aún una potencia imperial. En algunas regiones - como África se apropia de recursos naturales y endeuda a las economías insolventes. Pero no actúa como un imperio.

Algunos pensadores estiman que repetirá la trayectoria de Japón y Alemania, que en el pasado buscaron salidas externos a sus dificultades de crecimiento interno (DOCKÈS, 2013, p. 131-153).

Pero esta visión no registra el curso inverso que ha seguido China. Profundiza su expansión global a partir de una integración previa a la mundialización. Este modelo no regía a principios del siglo XX. Japón y Alemania competían con Estados Unidos o Inglaterra, sin compartir asociaciones económicas con sus rivales.

China es protagonista de la mundialización, pero tiene poco desenvuelto el elemento geopolítico-militar del imperialismo que ha desarrollado Rusia. Gestiona el segundo producto bruto del planeta, es el primer fabricante de productos industriales y recibe el mayor volumen de fondos del mundo. Pero esa gravitación económica no tiene correlato militar. 
El gigante oriental arrastra falencias en la modernización de sus fuerzas armadas, no participa de alianzas bélicas y carece de bases en el exterior. El pasado colonial todavía pesa en el divorcio de Taiwán y la parcial reintegración de Hong Kong (LOONG YU, 2015).

Hasta ahora el emergente asiático desenvuelve estrategias defensivas, especialmente en su principal canal de abastecimiento (el Mar de China). A diferencia de Rusia no ensaya respuestas militares - tipo Georgia o Siria - frente al hostigamiento norteamericano. Mantiene un perfil bajo y evita confrontaciones.

Esa auto-restricción de China coincide con el perfil cultural de un gigante que llegó tarde al mercado mundial. Con una lengua de uso puramente interno se limita a copiar la gestión transnacional de las empresas.

Pero su política exterior no guarda tampoco parentescos con la imagen angelical de una potencia empeñada en forjar relaciones internacionales equitativas (ESCOBAR, 2015). Esta mirada omite que el país actúa con parámetros capitalistas que excluyen la equidad y la cooperación.

China no inventa un capitalismo benévolo, ni se propone recuperar su antigua primacía durante el primer milenio. Se expande con reglas de opresión capitalistas, que no existían en ese lejanísimo antecedente.

La combinación de preeminencia económica y estrechez geopolítica que afronta China suscita distintos pronósticos. Algunos piensan que continuará un curso ascendente, fortaleciendo su alianza con Rusia para aprovechar el declive occidental (ZIBECHI, 2014).

Otros estiman que el país ya está muy integrado en la economía global y seguirá acumulando dólares o Bonos del Tesoro para mantener el modelo exportador (HUNG, 2015, p. 196-201). Pero como potencia no sustitutiva de Estados Unidos deberá lidiar con las tensiones de una integración económica socavada por rivalidades políticas.

Las vacilaciones del establishment norteamericano frente a China ilustran el desconcierto que provoca esta indefinición de rumbos. El estatus imperial del país es una incógnita del mismo tipo. 


\section{0 ¿BRASIL SUBIMPERIAL HOY?}

Brasil fue el principal modelo de Marini para caracterizar a los subimperios. ¿Encaja ese concepto con la realidad actual? No cabe duda que el país mantiene su condición de economía intermedia. Ese posicionamiento persiste por el tamaño y gravitación de sus mercados. En el 2005 desplazó a México en el tope regional y en términos absolutos su producto llegó a ocupar el sexto lugar mundial.

Esta incidencia se verifica también en el el rol de las multinacionales. Hay 11 firmas de origen brasileño entre las 100 principales compañías globales y las inversiones en el exterior pasaron del 0,1\% (1970) al 2,3\% (2006) del total global.

Las grandes compañías se han especializado en recursos naturales (Gerdau, Vale, Petrobras, Votorantim), construcción (Odebrecht, Andrade Gutiérrez) e ingeniería (Marcopolo, Sabó, Embraeer, WEG, Tigre). Han contado con el sostén de un gran banco estatal (BNDES) y tuvieron un desenvolvimiento superior a sus pares de Argentina o México (BUENO; SEABRA, 2010).

Pero la economía brasileña difiere del perfil que presentaba en los años 1960-1970. Durante las últimas décadas reapareció la especialización en exportaciones básicas, junto a un significativo retroceso de la industria. Esa regresión coexistió con el creciente endeudamiento del Estado. Los bancos y el agro-negocio han recuperado primacía frente a los industriales en el bloque de las clases dominantes.

Brasil perdió el aura de economía industrial ascendente. Los países asiáticos transformados en talleres del mundo han acaparado esa fisonomía. El declive fabril brasileño es muy relevante para un diagnóstico subimperial en los términos de Marini. El pensador marxista atribuía esa condición a incursiones externas derivadas del despunte manufacturero. Si esa esfera declina se replantea el estatus del país en la mirada dependentista.

En nuestra actualización, la dimensión económica no es tan relevante como el papel geopolítico, en la caracterización de un subimperio. Brasil ha consolidado en este plano su relevancia internacional. Forma parte de los BRICS, opera como la principal cancillería frente a cualquier crisis regional, es el interlocutor prioritario del Departamento de Estado y aspiró a un asiento en el Consejo de Seguridad de la Naciones Unidas. 
Pero también se ha confirmado la ambivalencia de sus gobiernos para liderar procesos de integración económica y conformación de bloques regionales. En las últimas décadas todos los presidentes vacilaron entre dos estrategias sin definir ninguna. No avanzaron en la inserción multilateral propia, ni en liderar una presencia sudamericana autónoma.

Las dudas en el primer terreno condujeron a frenar la promoción de una moneda común en la zona, bloquear la implementación del Banco del Sur y frustrar el manejo coordinado de las reservas acumuladas por la región. El MERCOSUR fue formalmente propiciado sin ningún acompañamiento práctico. Abundaron las proclamas pero no las iniciativas efectivas.

Como la expansión agro-exportadora de Brasil se consumó en gran medida fuera del vecindario, el interés por el resto del mundo prevaleció en desmedro de Sudamérica. Despertó más atención el Banco de los BRICS que el Banco del Sur y se amplió la participación en la cartera del FMI, a costa de la articulación financiera latinoamericana. Este divorcio entre intereses globales y regionales diluyó el perfil geopolítico del país.

En comparación a la época de Marini, Brasil afianzó su autonomía frente a Estados Unidos. Participa en organismos -como UNASUR o CELAC - alejados del tradicional sometimiento de la OEA. Pero esta ampliación de la acción propia no se tradujo en acciones subimperiales.

La ambigüedad de Brasil se verifica en el plano militar. Los gobiernos optaron por el rearme para proteger los recursos naturales. Modernizaron barcos, aviones y sistemas de detección para custodiar las fronteras y resguardar la Amazonía.

Pero desenvolvieron una sola incursión externa con la ocupación de Haití. Coordinaron ese operativo con Estados Unidos para cumplir las mismas funciones policiales que anteriormente ejercían los marines. Lejos de brindar auxilio humanitario contuvieron revueltas y aseguraron el orden semicolonial.

El carácter reaccionario de esa invasión salta a la vista, pero su impronta subimperial es controvertida. Brasil lideró un pelotón latinoamericano integrado por países como Uruguay, que nadie podría situar en ese estatus. El subimperialismo no se define por 
la simple participación en operaciones internacionales de custodia del orden capitalista.

Ciertamente Brasil encabeza la legión que interviene en Haití. Pero Marini no caracterizaba al subimperialismo por la presencia bélica en acciones propiciadas por el Pentágono. Por eso no aplicó el término a la intervención brasileña en la Segunda Guerra Mundial.

Su tesis apuntaba a resaltar acciones específicas de la clase dominante para reforzar el lucro de las multinacionales. Esta caracterización se aplica muy parcialmente al caso de Haití.

El espacio de Brasil para implementar políticas subimperiales en la coyuntura actual es estrecho. El desplazamiento de Dilma Rousseff en 2016 fue consumado por un trípode de parlamentarios corruptos, jueces y medios de comunicación, que reemplaza a los militares en la instrumentación de asonadas reaccionarias.

Extendieron a Brasil el nuevo tipo de "golpes blandos" que el establishment efectivizó previamente en Honduras y Paraguay. Estas acciones para-institucionales socavan la estabilidad requerida para implementar estrategias subimperiales. La restauración conservadora signada por el alineamiento total con el Departamento de Estado, sólo augura un prolongado periodo de crisis.

\section{COMPARACIONES CON OTROS CASOS}

Si se compara el nivel de intervención militar externa de Turquía con Brasil salta a la vista el abismo de injerencia que se verifica en ambos casos. Como el primer país ofrece un modelo de intervención subimperial actual, resulta forzado extender esa caracterización a la nación sudamericana. El mismo contrapunto podría establecerse con India.

Conviene recordar que Brasil no arrastra tradiciones centenarias de opresión, ni desarrolló acciones bélicas sistemáticas fuera de sus fronteras. Mantuvo una subordinación conservadora frente a las potencias mundiales, sin incursionar por ejemplo en el tipo de aventuras que perpetraron los militares argentinos en Malvinas. 
En las últimas décadas el gendarme más activo de Sudamérica ha sido Colombia. Con el pretexto de combatir el narcotráfico, el Pentágono instaló seis bases y adiestró una fuerza armada que ampara para-militares, amenaza a Venezuela y espía a todos los vecinos.

Ese ejército - guiado por marines e incorporado a la OTAN - es el principal represor de la región, pero no conforma un pelotón subimperial. Carece de la autonomía requerida para actuar en ese plano y responde a una clase dominante sin proyectos de supremacía zonal. Colombia se encuentra mucho más lejos que Brasil en cualquier clasificación de los subimperios.

La evolución reciente de Brasil presenta semejanzas con Sudáfrica. La principal economía del continente negro desenvolvió durante la mayor parte del siglo XX una activa intervención en sus zonas aledañas, para ampliar los negocios de las empresas localizadas en Johannesburgo y contrarrestar las rebeliones anticoloniales.

El término subimperialismo fue apropiadamente utilizado para calificar esa estrategia del Apartheid. El sistema racista de opresión interna operó en forma nítida como una fuerza contrarrevolucionaria externa. Presentó muchos parecidos con el prusianismo militar descripto por Marini (BOND, 2005).

Pero al igual que en Brasil, el problema aparece al momento de actualizar esa caracterización. La tesis subimperial podría ser mantenida, si se prioriza la expansión de las firmas sudafricanas bajo el neoliberalismo post-Apartheid.

Los gobiernos de ese periodo han sido bendecidos por el FMI. Cooptaron a las nuevas elites negras, para implementar políticas regresivas que potencian la desigualdad social, el endeudamiento y el saqueo de los recursos naturales del vecindario de Sudáfrica. La dominación financiera y el predominio de las empresas mineras de Johannesburgo son muy visibles en Congo y Angola (BOND, 2016). Aquí se verifica la analogía con las transnacionales brasileñas.

Pero con la extinción del Apartheid ha desaparecido la intervención militar externa explícita de las tropas de ese régimen. Tampoco perduran incursiones laterales como las implementadas 
por el Pentágono. La descarada intervención del imperialismo francés en sus viejas colonias no tiene correlato en África Austral.

La herencia legada por el régimen racista impide a los gobiernos sudafricanos utilizar la fuerza militar explicita fuera de sus fronteras. Ese recorte del margen de acción bélica externa, torna poco aplicable el término subimperial a la principal economía del continente negro.

Al igual que Brasil, Sudáfrica persiste como un subimperio sólo potencial. Confirmando el perfil variable de esa categoría no cumple ese rol en la actualidad.

\section{CONTROVERSIAS EN LA APLICACIÓN}

La continuada influencia de las empresas transnacionales que operan desde São Paulo es remarcada en la caracterización subimperial actual de Brasil (LUCE, 2015, p. 29-31). Esta mirada recuerda que durante la gestión del PT, las grandes empresas buscaron nuevamente compensaciones externas a las limitaciones del poder de compra local. El incremento del consumo interno no diluyó esa necesidad de mercados foráneos.

Las multinacionales incursionaron en negocios lucrativos en Sudamérica, generaron conflictos en Paraguay y Ecuador y compraron activos en Argentina. Lula y Dilma actuaron como lobistas de esas compañías perfeccionando la mediación diplomática de Itamaraty.

Pero ese expansionismo no determinó un perfil subimperial. Ningún gobierno del nuevo siglo recurrió a la supremacía militar o a la presión geopolítica explícita para apuntalar a esas empresas. Apelaron a la mediación en los conflictos que esas compañías tuvieron con los gobiernos radicales de Bolivia y Venezuela. Esa actitud contrasta con las posturas de los gobiernos militares de la época de Marini (MARTINS, 2011).

Otro contrapunto entre ambos periodos despunta en la solvencia de esas empresas. La expansión del pasado ha sido suc $\approx$ edida por el deterioro que salió a flote con la crisis de Odebrecht. Lula actuaba como abogado de esa empresa en sus desarreglos externos y Temer afronta un mega-escándalo de corrupción. 
Odebrecht utilizaba un colapsado sistema de coimas internacionales para ganar licitaciones. Varios competidores foráneos quieren apoderase ahora de los negocios de la compañía insignia de Brasil. Las limitaciones para sostener el flanco geopolítico del subimperialismo comienzan a extenderse a la órbita económica.

Algunos autores estiman que la brecha estructural entre ambos planos signó la historia del país. Señalan que Brasil siempre mantuvo una presencia en el mercado mundial superior a su gravitación geopolítica. Consideran que ese desbalance afianzó una formación híbrida, que combina rasgos de semicolonia privilegiada con perfiles de sub-metrópoli dependiente (ARCARY, 2016).

Esta caracterización es una variante del estatus intermedio resaltado por numerosos investigadores. Pero esa definición debería considerar, además, las novedosas fracturas entre la esfera económica y el ámbito político-militar. Se han potenciado países con atributos en el primer plano sin correspondencia en el segundo (Corea del Sur) y situaciones exactamente inversas (Rusia).

No es sencillo precisar la peculiaridad intermedia de Brasil que exploró Marini. Pero ese estatus se ubica muy lejos del ascenso del país al rango de "nueva potencia global", que ocupa el vacío dejado por el declive estadounidense (ZIBECHI, 2015).

No existe ningún segmento de la economía brasileña comparable a sus equivalentes de Estados Unidos, Europa o Japón. Tampoco en el plano geopolítico o militar, el país se equipara con alguno de los imperios en gestación. No implementan acciones exteriores análogas al despliegue bélico de Rusia en Georgia o Siria. Y no se visualiza el menor signo de equiparación con la presencia de China en África o el sur de Asia (SOTELO VALENCIA, 2015, p. 70-86).

La ubicación de Brasil en un lugar de potencia central tampoco cuaja con alguna teoría del imperialismo. El único fundamento conceptual sería la mirada pos-desarrollista, que asocia la irrupción de nuevos poderes con la dinámica depredadora del capitalismo extractivista. Pero en ese caso la conceptualización del imperio vuelve a asumir connotaciones vagas y desvinculadas de la lógica de la acumulación. 


\section{REPLANTEO Y UTILIDAD}

¿Cuál es la utilidad del concepto subimperialismo en la actualidad? Contribuye ante todo a comprender la estructura jerárquica del capitalismo contemporáneo. Confirma que en la cúspide de este sistema se sitúan potencias centrales - que han actuado hasta ahora bajo el comando estadounidense - y que en la base se ubica el gran conglomerado de países dominados.

En el medio de ambos polos se desenvuelven las distintas formaciones que operan como apéndices, rivales o asociados autónomos de los poderes dominantes. Todas esas sub-potencias buscan afianzar su hegemonía regional con posicionamientos distintos.

Los apéndices del imperialismo expanden ese poder en total sintonía con las estrategias de Washington, los imperios en formación chocan con ese centro y los subimperios desenvuelven acciones autónomas en coordinación o conflicto con las metrópolis.

La categoría subimperio es particularmente apropiada para entender el estado de guerra permanente, que impera en ciertas zonas para dirimir supremacía regional. Las subpotencias recurren a la acción bélica para hacer valer su predominio. Medio Oriente es el principal ejemplo de estos escenarios. Las rivalidades entre Turquía, Arabia Saudita e Irán se procesan en esos términos.

Esa competencia desestabiliza el orden mundial, como lo prueba el descontrol de las fuerzas yihadistas. Genera convulsiones que se proyectan al interior de Estados Unidos y Europa. El terrorismo se ha desbordado como consecuencia de la acción autónoma de los subimperios.

Este descontrol nunca se verifica en los países incorporados a la estructura del Pentágono o la OTAN. Es el caso de Israel, Canadá o Australia, que no actúan como subimperios sino como prolongaciones del imperialismo.

La categoría tampoco se aplica a las principales potencias en conflicto estructural con Estados Unidos. Rusia y China conforman imperios en formación que actúan a nivel global y no solo regional. Mantienen vínculos de hostilidad y no de asociación con Washington. En estos casos no rige el concepto de subimperio. 
Aquí la categoría sirve para ilustrar - por contraposición - cuál es el estatus de los principales adversarios del imperialismo occidental.

Los subimperios registran intensas mutaciones por su vulnerable inserción en la división internacional del trabajo y en el orden geopolítico global. Esos ascensos y descensos modifican su perfil. Junto a los subimperios en acción (Turquía), recomposición (Irán) o surgimiento (Arabia Saudita), otros no ejercen en la actualidad ese rol (Sudáfrica y Brasil).

La ausencia de despliegue militar de envergadura fuera de sus fronteras determina ese pasaje de subimperios efectivos a potenciales. El fin del Apartheid en el primero caso y el desarme atómico en el segundo fueron determinantes del tránsito de una posición a otra.

El subimperio ofrece un concepto provechoso para comprender la realidad contemporánea. Pero se requiere una reinterpretación de la noción distanciada de su aplicación original. Este replanteo valoriza el significativo geopolítico del concepto, en función de los grandes cambios mundiales registrados en los últimos 40 años.

¿Pero cuál es el nexo del subimperialismo con las categorías específicamente económicas de la Teoría Marxista de la Dependencia? ¿Cómo se relaciona con la superexplotación? Abordaremos este tema en nuestro próximo texto.

\section{REFERENCIAS}

AMIN, S. El mundo árabe: raíces y complejidades de la crisis. La Habana: Ruth Ediciones, 2011.

AMIN, S. Transnational capitalism or collective imperialism?. Social Network Unionism, 25 jul. 2012. Disponible en: $<$ https://snuproject.wordpress.com/2012/07/25/transnationalcapitalism-or-collective-imperialism-by-samir-amin/>. Acceso en: 21 jun. 2017.

ANNIS, R. The Russia is imperialist thesis is wrong. Truthout, 18 jun. 2014. Disponible en: <http://www.truth-out.org/news/ item/24428-the-russia-as-imperialist-thesis-is-wrong-and-abarrier-to-solidarity-with-the-ukrainian-and-russian-people $>$. Acceso en: 19 jun. 2017. 
ARCARY, V. Uma nota sobre o lugar do Brasil no mundo em perspectiva histórica. Blog Esquerda On Line, 20 dec. 2016. Disponible en: <http://blog.esquerdaonline.com/? $\mathrm{p}=7760>$. Acceso en: 19 jun. 2017.

ARMANIAN, N. La rivalidad entre Rusia e Irán remodela el mercado del gas de Eurasia. Blog Público, 30 ene. 2016. Disponible en: http://blogs.publico.es/puntoyseguido/3144/la-rivalidad-entrerusia-e-iran-remodela-el-mercado-del-gas-en-eurasia/. Acceso en: 19 jun. 2017.

BATOU, J. Cien años después, lo que plantea el reconocimiento del genocidio armenio. Viento Sur, 23 abr. 2015. Disponible en: http:// vientosur.info/spip.php?article10005. Acceso en: 19 jun. 2017.

BEHROUZ, F. El papel de Irán en la tragedia siria. Viento Sur, 16 ene. 2017._Disponible en: <http://vientosur.info/spip. php?article12116>. Acceso en: 19 jun. 2017.

BOND, P. El imperio norteamericano y el subimperialismo sudafricano. In: PANITCH, L.; LEYS, C. (eds.). El Imperio Recargado. Buenos Aires: CLACSO, 2005. p. 251 - 270.

BOND, P. BRICS and the sub-imperial location. In: BOND, P.; GARCIA, A. BRICS An Anti-Capitalist Critique. Chicago: Haymarket, 2015. p. $15-26$.

BOND, P. BRICS banking and the debate over sub-imperialism. Committee for the Abolition of Illegitimate Debt, 15 nov. 2016. Disponible en: <http://www.cadtm.org/spip. php?page=imprimer\&id_article=13946> . Acceso en: 19 jun. 2017.

BUENO, F.; SEABRA, R. A teoria do subimperialismo brasileiro: notas para uma (re)discussão contemporânea. In: COLÓQUIO INTERNACIONAL MARX E ENGELS, 6., 2010, São Paulo. Anais... São Paulo: Unicamp, 2010. p. 01 - 10. Disponible en: <https:// www.ifch.unicamp.br/formulario_cemarx/selecao/2009/ trabalhos/a-teoria-do-subimperialismo-brasileiro.pdf>. Acceso en: 19 jun. 2017.

ÇAĞLI, E. On Sub-imperialism: Regional Power Turkey. Marksist Tutum, 28 jul. 2009. Disponible en: <http://en.marksist.net/elif_ cagli/on_sub_imperialism_regional_power_turkey.htm>. Acceso en: 19 jun. 2017. 
DEMOCRATIC Socialist Party. The role of Australian imperialism in the Asia-Pacific region. International Journal of Socialist Renewal, 27 sept. 2011. Disponible en: <http://links.org.au/ node/116>. Acceso en: 19 jun. 2017.

DOCKÈS, P. Mondialisation et impérialisme à l'envers. In: ANDREFF, W. (dir.). La mondialisation, stade supreme du capitalisme. Nanterre: Presses Universitaires de Paris Ouest, 2013. p. 129 - 151.

DOLCEROCCA, A.; TERZIOGLU, G. Interview with Boris Kagarlitsky on Ukraine. The new cold war: Ukraine and beyond, mar. 2015. Disponible en: <www.newcoldwar.org/interview-withboris-kagarlitsky-on-ukraine-march>. Acceso en: 19 jun. 2017.

DZARASOV, R. Modern Russia as semi-peripheral, dependent capitalism. In: BOND, P.; GARCIA, A. BRICS An Anti-Capitalist Critique. Chicago: Haymarket, 2015. p. $200-201$.

ESCOBAR, P. ¿Pueden China y Rusia echar a Washington a empujones de Eurasia?. Rebelión, 10 sep. 2014. Disponible en: $<$ rebelion.org/noticia.php?id=190582 >. Acceso en: 19 jun. 2017.

ESCOBAR, P. ¿Año de la Cabra, Siglo del dragón?. Ojos para la Paz, 16 mar. 2015. Disponible en: <www.ojosparalapaz.com/anode-la-cabra-siglo-del-dragon/>. Acceso en: 19 jun. 2017.

HUNG, H. China and the lingering Pax Americana. In: BOND, P.; GARCIA, A. BRICS An Anti-Capitalist Critique. Chicago: Haymarket, 2015. p. $254-260$.

JAHANPOUR, F. Las raíces profundas de la rivalidad entre suníes y chiíes. Inter Press Service - IPS Noticias, 03 nov. 2014. Disponible en: <http://www.ipsnoticias.net/2014/11/las-raicesprofundas-de-la-rivalidad-entre-sunies-y-chiies/>. Acceso en: 19 jun. 2017.

KATZ, C. Argumentos pela palestina. Revista Outubro, São Paulo, n. 15, p. $79-120,2007$.

El tormentoso debut de Trump. La página de Claudio Katz, 02 feb. 2017a. Disponible en: <www.lahaine.org/katz>. Acceso en: 21 jun. 2017.

Subimperialismo I: revisión de un concepto. La página de Claudio Katz, 04 abr. 2017b. Disponible en: <www.lahaine.org/ katz>. Acceso en: 21 jun. 2017. 
KOWALEWSKI, Z. M. Impérialisme russe. Inprecor, $\mathrm{n}$. 609-610, 2014. Disponible en: <http://www.inprecor. $\mathrm{fr} / \sim 163$ e 5 f589197a 4 f0addb436d / article-RussieImp\%C3\%A9rialisme\%20russe?id=1686>. Acceso en: 19 jun. 2017.

LUCE, M. S. Sub-imperialism, the highest stage of dependent capitalism. In: BOND, P.; GARCIA, A. BRICS An Anti-Capitalist Critique. Chicago: Haymarket, 2015. p. $27-44$.

MARTINS, C. E. O pensamento social e a atualidade da obra de Ruy Mauro Marini. Revista Crítica Marxista, São Paulo, n. 32, p. 127 146, 2011. Disponible en: <www.ifch.unicamp.br/criticamarxista/ arquivos_biblioteca/artigo236artigo6.pdf>. Acceso en: 19 jun. 2017.

MORALES RUVALCABA, D. E. En las entrañas de los BRCIS: Análisis de la naturaleza semiperiférica de Brasil, Rusia, India y China. Austral: Revista Brasileira de Estratégia e Relações Internacionais, Porto Alegre, v. 2, n. 4, p. 147 - 181, 2013. Disponible en: <http://www19. iadb.org/intal/intalcdi/PE/2014/13593.pdf>. Acceso en: 19 jun. 2017.

PETRAS, J. The foundation of the US Empire: Axes of Evil. The James Petras Website, 19 jul. 2014. Disponible en: <http:// petras.lahaine.org/?p=1995>. Acceso en: 19 jun. 2017.

POZO-MARTIN, G. Russia's neoliberal imperialism and the Eurasian challenge. In: BOND, P.; GARCIA, A. BRICS An AntiCapitalist Critique. Chicago: Haymarket, 2015. p. $206-229$.

PRÉSUMEY, V. Les impérialismes au miroir de la crise ukrainienne. Inprecor, n. 611, 2015. Disponible en: <http:// www.inprecor.fr/article-Chaos\%20g\%C3\%A9opolitique-Les\%20 imp\%C3\%A9rialismes\%20au\%20miroir\%20de\%20la\%20crise\%20 ukrainienne?id=1703>. Acceso en: 19 jun. 2017.

ROUSSET, P. China: Un imperialismo en construcción. Viento Sur, 15 jul. 2014. Disponible en: <http://vientosur. info/spip.php?article9230>. Acceso en: 19 jun. 2017.

ROZHIN, B. Un año después: la izquierda y Maidán. Rebelión, 24 abr. 2015. Disponible en: <www.rebelion.org>. Acceso en: 19 jun. 2017.

SAVRAN, S. Turkey: Atlanticism versus Rabiism. The Bullet Socialist Project, 29 jul. 2016. Disponible en: <http:// socialistproject.ca/bullet/1286.php>. Acceso en: 19 jun. 2017. 
SHORT, J. China's Rise: Strength and Fragility by Au Loong Yu. International View of Point, 23 mar. 2015. Disponible en: $<$ www.internationalviewpoint.org/spip.php?article3936>. Acceso en: 21 jun. 2017.

SLEE, C. Are Russia and China imperialist powers?. Inter Press Service - IPS Noticias, 7 abr. 2014. Disponible en: <http://links. org.au/node/3795>. Acceso en: 19 jun. 2017.

SOTELO VALENCIA, A. Sub-Imperialism Revisited: Dependency Theory in the Thought of Ruy Mauro Marini. Leida, Países Baixos: Brill, 2015.

ZIBECHI, R. China y Rusia: Las locomotoras del nuevo orden mundial. América Latina en Movimiento Online, 28 nov. 2014. Disponible en: <http://www.alainet.org/es/active/79077>. Acceso en: 19 jun. 2017.

. Brasil. ¿El nuevo imperialismo?. Lavaca, 04 nov. 2015. Disponible en: <http://www.lavaca.org/libros/brasil-el-nuevoimperialismo/>. Acceso en: 21 jun. 2017. 